\title{
PENERAPAN MULTIMEDIA AUDIO GALERY ILEARNING COMMUNITY AND SERVICES (MAGICS) SEBAGAI MEDIA PENYIMPANAN DOKUMENTASI PADA PERGURUAN TINGGI RAHARJA
}

\author{
Hani Dewi Arriesanti ${ }^{1}$ \\ Muhamad Yusup ${ }^{2}$ \\ Ceria Marcelina $^{3}$ \\ e-mail: hani.dewi@raharja.info,yusup@raharja.info,ceria@raharja.info
}

Diterima : 25 Nopember 2013/ Disetujui : 11 Desember 2013

\begin{abstract}
Technology information had a critical role in human life, no exception in education. One of the products technology that is occupied in education is multimedia. Perguruan Tinggi Raharja which applies the methods of iLearning need multimedia in realizing concept $4 B$. The application of multimedia was meant to make efficiency and effectiveness in the procurement information in form of documentation such as image, audio, and video. However Green Documentation as a file storage in Perguruan Tinggi Raharja is still less than optimal, so the documentation is spread across multiple storage online media. This is because either Green Documentation and media online were available haven't been enough to be storage requirements which covers images, audio, and video in one integrated place that you can share. As a result, students having trouble finding documentation of activities held by the campus. MAGICS is an online media which allows all documentation can be arranged neatly to facilitate searches. This paper tries to describe the problems and solving in an information systems, especially in terms of documentation. Implementation of MAGICS can be used as a solution for providing file storage and file sharing in the application of learning method (iLearning).
\end{abstract}

Keywords : Documentation, Online media, iLearning, MAGICS

1. . Dosen Jurusan Sistem Komputer, STMIK Raharja

Jl. Jend Sudirman No. 40 Modern Cikokol-Tangerang Telp. 5529692

2. . Dosen Jurusan Sistem Informasi, STMIK Raharja

Jl. Jend Sudirman No. 40 Modern Cikokol-Tangerang Telp. 5529692

3. . Mahasiswa Jurusan Sistem Informasi, STMIK Raharja

Jl. Jend Sudirman No. 40 Modern Cikokol-Tangerang Telp. 5529692 


\begin{abstract}
ABSTRAKSI
Saat ini teknologi informasi memegang peranan penting dalam kehidupan manusia, tidak terkecuali dalam dunia pendidikan. Salah satu produk teknologi yang dimanfaatkan dalam dunia pendidikan adalah multimedia. Perguruan Tinggi Raharja yang menerapkan metode pembelajaran iLearning sangat membutuhkan multimedia dalam mewujudkan konsep 4B. Penerapan multimedia ini bertujuan untuk mewujudkan efisiensi dan efektivitas dalam penyediaan fasilitas informasi berupa dokumentasi yang berbentuk gambar, audio, maupun video. Namun Green Documentation yang berfungsi sebagai wadah dokumentasi pada Perguruan Tinggi Raharja masih kurang optimal, sehingga penyimpanan dokumentasi tersebar di beberapa media online. Hal demikian terjadi karena baik Green Documentation maupun media online yang tersedia belum memenuhi kebutuhan yang mencakup penyimpanan gambar, audio, dan video dalam satu tempat yang terintegrasi. Akibatnya mahasiswa kesulitan mencari dokumentasi kegiatan yang digelar oleh kampus karena tidak ada media penyimpanan yang terpusat. MAGICS merupakan sebuah media online yang memungkinkan semua dokumentasi dapat tersusun rapi hingga memudahkan dalam pencarian. Tulisan ini mencoba untuk menjabarkan permasalahan serta pemecahan masalah yang dihadapi pada suatu sistem informasi khususnya dalam hal dokumentasi. Implementasi dari MAGICS ini dapat digunakan sebagai satu solusi untuk menyediakan wadah dokumentasi dan file sharing dalam penerapan metode pembelajaran iLearning.
\end{abstract}

Kata kunci : Dokumentasi, Media online, iLearning, MAGICS

\title{
PENDAHULUAN
}

Teknologi internet telah diterapkan dalam setiap aspek kehidupan. Mulai dari aspek sosial, pemerintahan, pertahanan, pendidikan, bisinis dan banyak hal lainnya. Dalam sebuah instansi pendidikan, penggunaan internet dimanfaatkan sebagai alat bantu pembelajaran dan komunikasi. Contohnya pada SMA Pramita yang memanfaatkan internet guna menunjang kegiatan belajar mengajar, lalu SMAN 1 Tangerang dalam proses penerimaan siswa baru secara online. Serta SMAN 2 Tangerang yang membuat forum siswa online.

Sebagai sebuah instansi pendidikan, Perguruan Tinggi Raharja yang notabenenya bergerak di bidang komputer juga memanfaatkan internet yang dipadukan dengan metode pembelajaran yang dinamakan iLearning. Dalam buku berjudul “iLearning an Effective Learning Method for Higher Education”, Untung Rahardja (2011) menjelaskan bahwa iLearning adalah sistem pembelajaran modern dan terbaru dalam dunia pendidikan yang berbasis 4B yaitu belajar, bermain, bekerja, dan berdoa. Apabila diimplementasikan sebagai arsitektur 4B iLearning, tampak pada gambar berikut ini. 


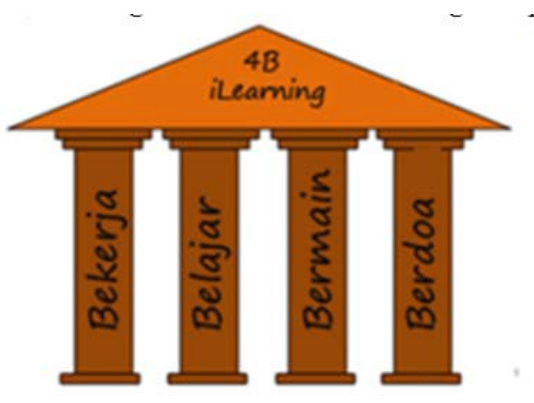

Gambar 1. Arsitektur iLearning 4B

Terlihat dari gambar di atas, 4 (empat) sistem pembelajaran iLearning yang diterapkan Perguruan Tinggi Raharja saling berhubungan dan berkaitan satu sama lain sehingga membentuk suatu bangunan kokoh yaitu iLearning. Selain didasarkan oleh keempat pilar (4B), iLearning juga ditunjang dengan beberapa infrastuktur seperti pada gambar di bawah ini.

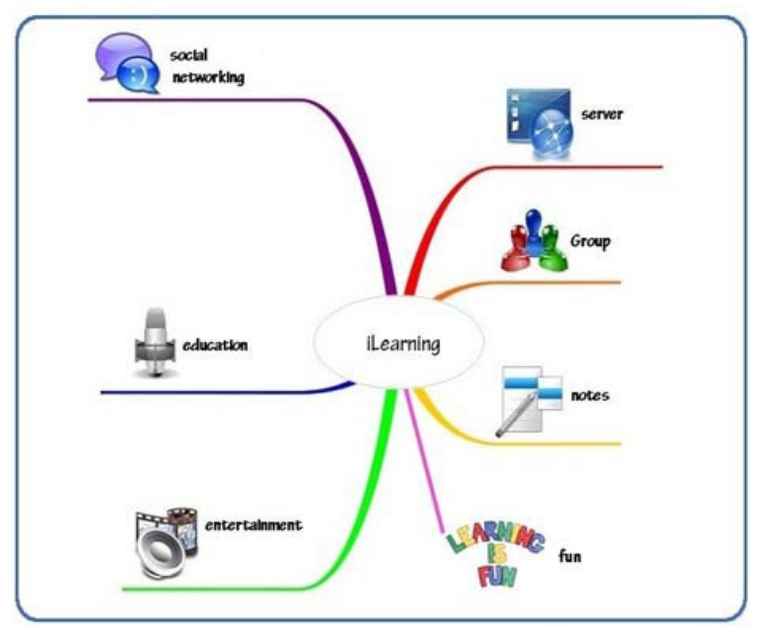

Gambar 2. Infrastruktur iLearning

Dari infrastrukturiLearning, dapat dilihat bahwa aktifitas perkuliahan dilakukan dengan menyenangkan karena didalamnya mencakup beberapa hal yang telah digambarkan pada gambar 2 di atas. Kita bisa belajar sambil melakukan social networking, membuat group, merangkai semua catatan dengan note serta mendapatkan hiburan dengan aplikasi entertainment. Tentunya hal ini tidak 
bertentangan dengan tujuan awal dibangunnya iLearning, yaitu mengedepankan education.

Bila diperhatikan pada infrastruktur iLearning tersebut, hampir semuanya berkaitan dengan multimedia, terutama dari segi entertainment. Demi mendukung pembelajaran iLearning, multimedia berfungsi sebagai sarana pembelajaran efektif dalam penyerapan bahan ajar. Selain itu, multimedia juga berperan sebagai penyimpanan data-data berupa tugas atau dokumentasi pribadi, serta fasilitas untuk memberikan informasi rekaman kegiatan kampus berupa dokumentasi foto ataupun video.

Sebagian besar perguruan tinggi di Indonesia sudah memiliki website untuk menyimpan seluruh kegiatan maupun dokumentasi yang telah diselenggarakan oleh kampus, seperti Podcast (www.podcast.ui.ac.id) yang dimiliki oleh Universitas Indonesia, UMNtv (www.tv.umn.ac.id) yang dimiliki oleh Universitas Multimedia Nusantara, serta UMB Video (www.video.mercubuana.ac.id) yang dimiliki oleh Universitas Mercu Buana. Demikian juga dengan Perguruan Tinggi Raharja yang telah memiliki Green Documentation untuk penyimpanan dokumentasi kegiatan kampus berupa foto.

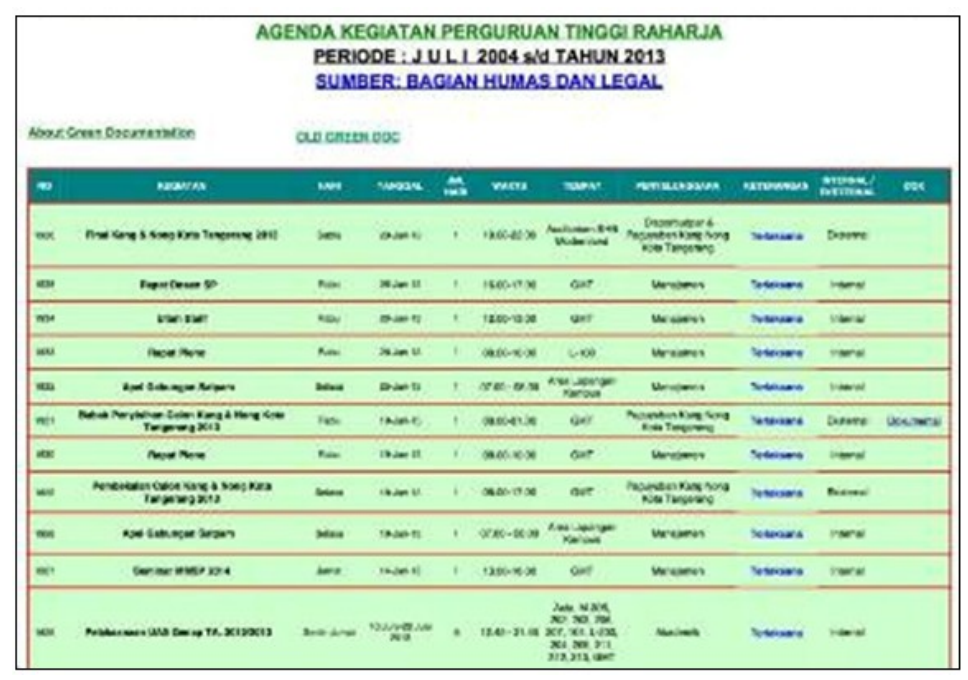

Gambar 3. Green Documentation

Namun, penggunaan Green Documentation masih belum maksimal. Sistem yang berjalan ini dirasa belum optimal karenamasih banyakmahasiswa yang kesulitan untuk mendapatkan dokumentasi pada website Raharja yang hanya bisa diakses 
pada server lokal. Selain itu Green Documentation juga tidak mencakup semua kebutuhan tersimpannya file seperti video dan audio. Hal tersebut mengakibatkan kurangnya minat para Pribadi Raharja untuk menggunakannya sehingga timbul rasa tidak puas terhadap sistem berjalan dan beralihnya penggunaan Green Documentation ke media penyimpanan online yang tersedia di internet.

Dari permasalahan tersebut, maka diperlukan suatu sistem yang dapat menyajikan informasi dengan mudah, cepat dan akurat, serta memuaskan bagi mahasiswa. Oleh karena itu, Perguruan Tinggi Raharja sebagai salah satu lembaga pendidikan unggulan, berusaha menyelesaikannya. Dengan memanfaatkan ilmu teknologi, Perguruan Tinggi Raharja mencoba membuat suatu media penyimpanan dokumentasi secara online melalui internet yang berbasis open source.

\section{PERMASALAHAN}

Multimedia diperlukan sebagai wadah yang dapat menampung segala bentuk dokumentasi. Dan setiap dokumentasi harus disimpan dengan baik dan rapi agar dapat memberikan informasi yang akurat. Untuk itu diperlukan suatu media yang dapat menunjang kebutuhan penyimpanan semua jenis dokumentasi. Namun, media penyimpanan yang berjalan pada Perguruan Tinggi Raharja belum optimal dikarenakan beberapa permasalahan. Intisari dari permasalahan sistem pendokumentasian yang berjalan saat ini digambarkan dalam bentuk Mind Mapping, seperti gambar berikut :

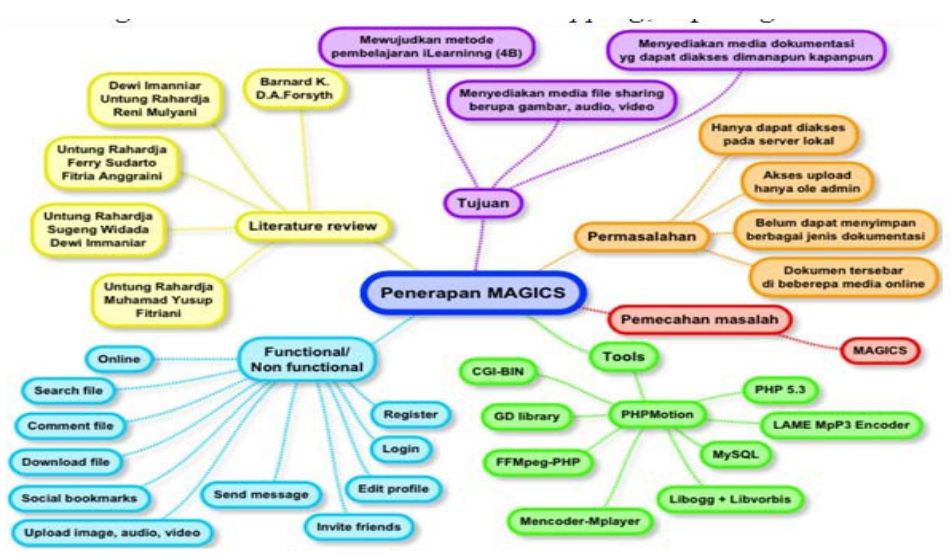

Gambar 4. Mind Mapping Penerapan MAGICS 
Di dalam Mind Mapping terdapat 4 (empat) permasalahan yang ada pada sistem berjalan, yaitu permasalahan pertama adalah website hanya dapat diakses pada server lokal. Permasalahan kedua, akses upload hanya oleh admin. Permasalahan ketiga, belum dapat menyimpan berbagai jenis dokumentasi. Dan permasalahan ke empat, dokumen tersebar di beberapa media online.

Penjabaran dari permasalahan pertama tentang website hanya dapat diakses pada server lokal, dalam hal ini mahasiswa yang ingin melihat dan meng-upload dokumentasi kegiatan kampus harus datang ke kampus dan membuka Green Documentation pada komputer yang terkoneksi dengan jaringan lokal. Kemudian permasalahan kedua mengenai akses upload hanya oleh admin. Apabila kita hendak meng-upload file tidak dapat dilakukan secara mandiri, karena di dalam Green Documentation kita hanya dapat melihat dan tidak bisa melakukan login ataupun memberi komentar pada foto. Lalu pada permasalahan ketiga mengenai belum dapat menyimpan berbagai jenis dokumentasi. Green Documentation hanya dapat menyimpan file berupa foto, sementara multimedia yang mendukung pembelajaran iLeraning terdiri dari foto, audio, dan video. Pada permasalahan keempat dokumen tersebar di beberapa media online. Hal ini terjadi karena Green Documentation tidak dapat meyimpan file secara keseluruhan, hak upload hanya oleh admin, serta aksesnya hanya pada server lokal, maka mahasiswa menyimpan file di beberapa media online, seperti di Facebook dan YouTube. Akibatnya dokumentasi tersebar sehingga kesulitan untukpencarian file.

\section{PEMECAHAN MASALAH}

Dalam mewujudkan konsep pembelajaran iLearning, salah satu aspek yang mendukung adalah multimedia. Penggunaan multimedia dapat dilakukan bila tersedia sebuah media yang dapat menyimpan dokumentasi. Berdasarkan permasalahan yang sudah dijabarkan di atas, dapat disimpulkan bahwa Green Documentation belum dapat memenuhi kebutuhan Pribadi Raharja saat ini.

Oleh karena itu perlu dilakukan perubahan terhadap sistem yang lama dengan sistem baru yang dinamakan MAGICS (Multimedia Audio Gallery iLearning Community and Services). Perancangan MAGICS dilakukan pada sebuah software open source yang tersedia di internet yaitu PHPMotion. Penggunaan MAGICS dapat mengatasi semua kekurangan yang menjadi permasalahan pada Green Documentation. MAGICS memiliki beberapa kelebihan diantaranya dapat diakses kapanpun dan dimanapun, penyimpanan file terdiri dari foto, audio, dan video, seluruh Pribadi Raharja dapat melakukan login untuk meng-upload dokumentasinya sendiri, 
terdapat fitur comment dan social bookmarks. Serta seluruh file yang di-upload tersimpan secara terpusat di dalam sebuah server yang aman. Kelebihan yang dimiliki ini merupakan solusi dari permasalahan Green Documentation.

Tetapi dari kelebihan yang ada, MAGICS juga masih jauh dari sempurna. MAGICS memiliki keterbatasan utama yaitumemerlukan jaringan internet yang cukup kuat agar akses MAGICS yang dilakukan oleh mahasiswa maupun civitas akademik berjalan lancar dan proses upload file berjalan cepat. Namun dengan keterbatasan ini, MAGICS tetap menawarkan fasilitas yang cukup untuk membuat sebuah program mediapenyimpanan dokumentasi kegiatan kampus.

Untuk memudahkan penjabaran dari sitem MAGICS, maka dilakukan cara alternatif penggambaran sistem melalui alur flowchart. Di bawah ini merupakan alur flowchart program MAGICS.

1. Flowchart Register MAGICS

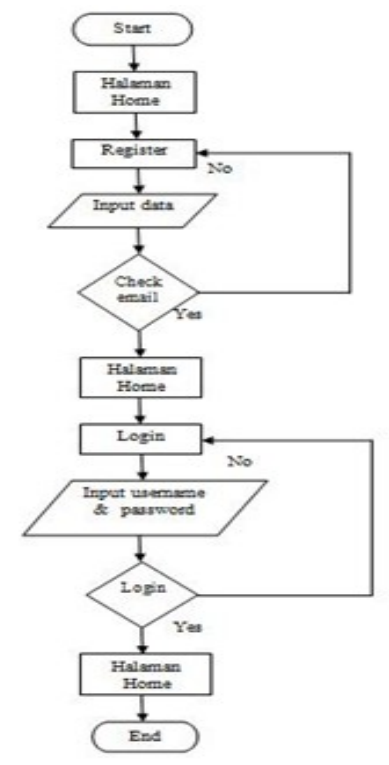

Gambar 5. Flowchart Register MAGICS

Pada flowchart di atas menjelaskan alur register atau registrasi untuk menjadi member. Langkah awalnya yaitu dengan mengkases URL www.magics.co. Pribadi Raharja akan mengisi form register dengan menginputkan data pribadi. Sebagai tindakan pengamanan, MAGICS telah memiliki default alamat email berdomain raharja.co dan raharja.info untuk menghindari adanya spammers. Jika data yang 
dimasukkan valid, maka status member akan didapatkan. Dengan username dan password yang sudah diinputkan saat register, member dapat login ke dalam MAGICS untuk melakukan kegiatan seperti upload dan download file berupa image, audio maupun video serta mengedit profile dan memberi komentar.

2. Flowchart Pengunggahan File

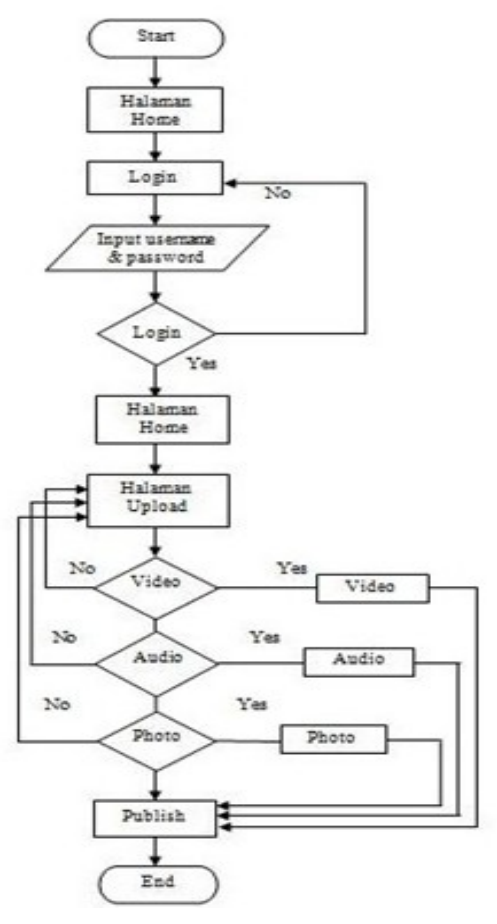

\section{Gambar 6. Flowchart Pengunggahan File}

Pada flowchart di atas menjelaskan alur pengunggahan file. Langkah awalnya yaitu mengkases URL www.magics.co lalu login. Setelah berhasil melakukan login, maka dapat melakukan kegiatan seperti pengunggahan atau upload file berupa image, audio maupun video. Kemudian file dapat di-publish untuk di-share agar dapat dilike atau dikometari.

Diagram rancangan sistem MAGICS dapat pula dijabarkan melalui Use Case Diagram yang menggambarkan kebutuhan sistem dari sudut pandang User dan memfokuskan pada proses komputerisasi. Untuk melihat peranan dari komponen 
yang terlibat di dalam sistem MAGICS, dapat dilihat pada gambar use case di bawahini:

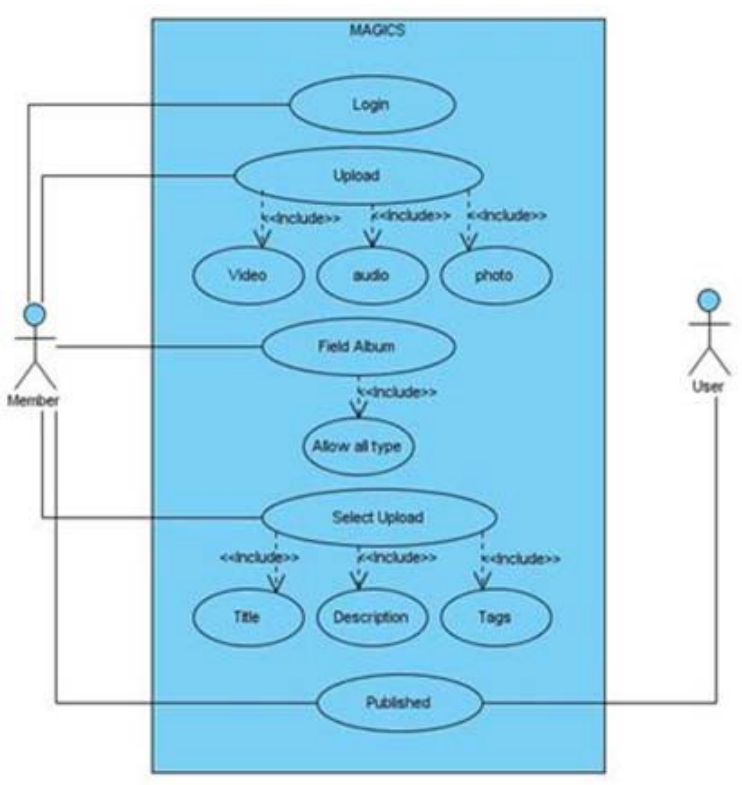

Gambar 7. Use Case Diagram Pengunggahan File

Use case pada dasarnya merupakan gambaran dari proses sistem secara keseluruhan yang melibatkan actor dalam hal penggunaan. Dalam use case diagram pengunggahan file ini terdapat 2 actor yang terlibat pada sistem MAGICS, dimana masing-masing actor memiliki hak akses yang berbeda. Member (actor 1) melakukan login pada MAGICS dengan membuka portal alamat www.magics.co. Setelah member berhasil login, akan terarah pada halaman upload. Pada halaman upload, member diberikan pilihan untuk meng-upload video, audio ataupun photo. Setelah memilih salah satu diantaranya, member akan mengisi field album, kemudian melakukan pengambilan file yang hendak di-upload. Bila file sudah ditentukan, member menekan tombol upload agar file berhasil ter-publish. Sedangkan untuk User (actor 2) hak aksesnya hanya dapat melihat file yang telah di-publish.

Penerapan sistem MAGICS ini diharapkan dapat membantu Pribadi Raharja dalam kemudahan mengakses media penyimpanan dimanapun dan kapanpun dalam 
kaitannya dengan pembelajaran iLearningdan diharapkan dapat bergunabagi Pribadi Raharja dalam mendapatkan informasi yang akurat, cepat dan up to date.

Listing Program

Di bawah ini merupakan listing program Multimedia Audio Gallery iLearning Community and Services pada Perguruan Tinggi Raharja, yaitu sebuah script dari proses upload. Berikut listing programnya :

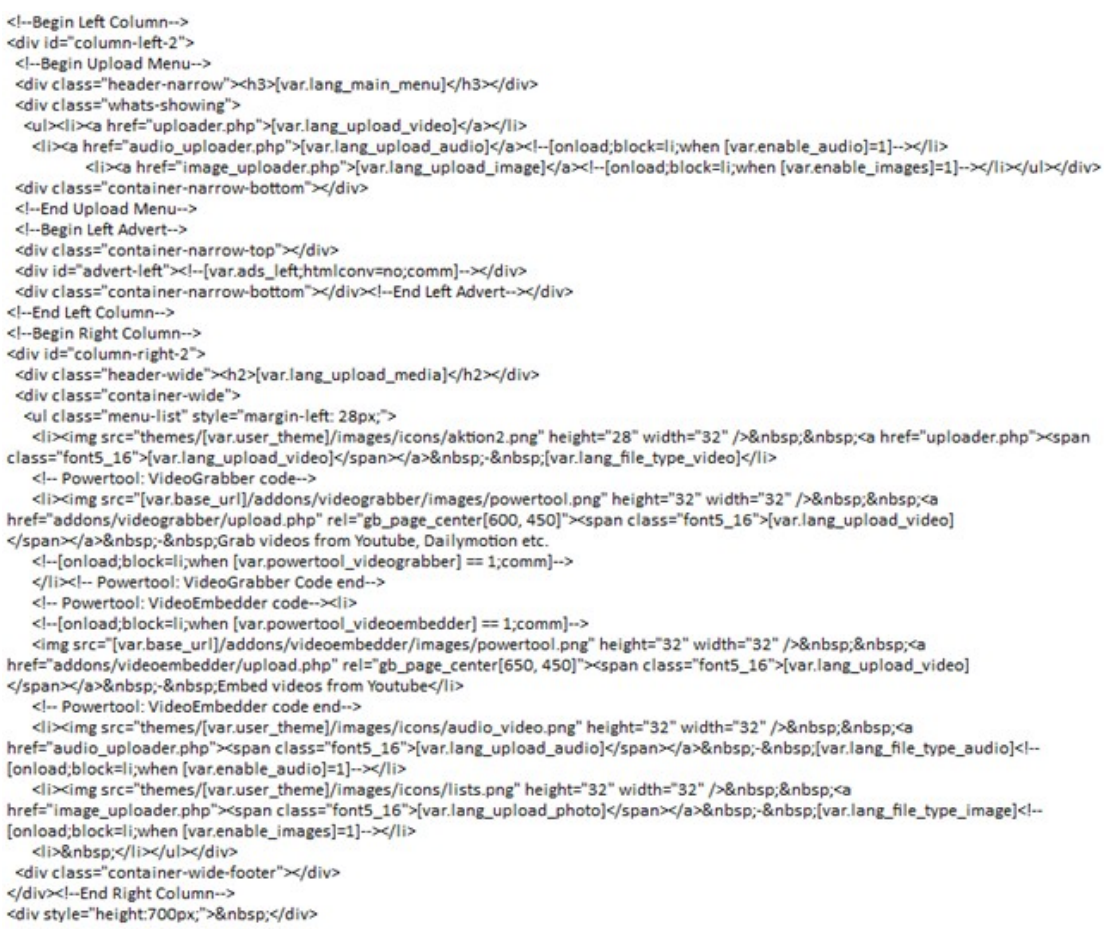

\section{PEMBAHASAN}

\section{Pengertian Internet}

Menurut eWolf Community (2012), "Internet merupakan singkatan dari Interconnection Networking, yaitu jaringan komputer dalam skala dunia. Internet terdiri dari banyak jaringan komputer lokal yang saling terhubung sehingga membentuk jaringan global dengan segala macam aturan (protokol). Protokol utama yang 
digunakan saat ini adalah TCP/IP (Transmission Control Protocol/Internet Protocol), yaitu sekumpulan aturan untuk komunikasi data antar komputer dalam suatu jaringan”. Dalam pengertian lain internet adalah komputer yang terhubung melalui jaringan dan saling berkomunikasi dengan waktu dan wilayah yang tak terbatas.

\section{Pengertian Multimedia}

Menurut Hofstetter (2001), multimedia adalah penggunaan komputer untuk menyajikan dan menggabungkan teks, suara, gambar, animasi dan video dengan alat bantu (tool) dan koneksi (link) sehingga pengguna dapat melakukan navigasi, berinteraksi, berkarya dan berkomunikasi. Multimedia sering digunakan dalam dunia hiburan. Selain dari dunia hiburan, Multimedia juga dimanfaatkan dalam dunia pendidikan dan bisnis. Di dunia pendidikan, multimedia digunakan sebagai media pengajaran, baik dalam kelas maupun secara sendiri-sendiri. Di dunia bisnis, multimedia digunakan sebagai media profil perusahaan, profil produk, bahkan sebagai mediainformasi dan pelatihan dalam sistem e-learning.

\section{Pengertian Dokumentasi}

Menurut Poerwadarminta, W.J.S. pada Kamus Umum Bahasa Indonesia (2007), pengertian dokumentasi yaitu pemberian atau pengumpulan bukti-bukti dan keterangan (seperti kutipan-kutipan dari surat kabar dan gambar-gambar). Sedangkan definisi lainnya adalah pekerjaan mengumpulkan, menyusun, dan mengelola dokumen-dokumen literer yang mencatat semua aktivitas manusia dan yang dianggap berguna untuk dijadikan bahan keterangan dan penerangan mengenai berbagai soal (Sulistyo Basuki, 1996). Dokumen sebagai obyek menyediakan informasi yang dapat dibedakan menurut sifatnya menjadi 2 jenis yaitu dokumen tekstual yaitu yang isinya dalam bentuk teks tertulis baik berupa huruf maupun angka. Sedangkan dokumen nontekstual disajikan dalam bentuk dokumen ikonik (peta, atlas, cetak biru, denah, grafik, poster, lukisan, foto, dan slaid), suara (rekaman, piringan hitam, kaset), audio-visual (film, video, TV), dan dokumen yang bersifat material (bola dunia, karya artistic, huruf braillle, mainan peraga).

\section{Pengertian Open Source}

Kata “open source” pertama kali muncul pada sebuah rapat di Palo Alto California. Ketika itu, Netscape yang merupakan pengembang browser Navigator ingin melepaskan kode sumber dari produk dengan nama Mozilla di bulan Januari 
1998. Merekan ingin membedakan diri dan menghindari konfrontasi ideologis maupun konotatif dengan istilah Free Software yang dipelopori oleh Richard Stallman.

Istilah Open Source lazim diterapkan pada kode sumber (source code) dari software yang dibuat untuk kepentingan public secara umum dengan tidak adanya batasan hak atas kekayaan intelektual. Prinsip ini menyediakan kebebasan kepada user untuk membuat isi sebuah software secara bertahap maupun berkolaborasi.

\section{Pengertian PHPMotion}

PHPMotion adalah open source video sharing yang mempunyai fitur hampir sama dengan yang dimiliki youtube.com. PHPmotion disebut juga sebagai media sharing CMS (Content Management System) karena sangat mendukung dalam keperluan sharing media file seperti video, musik, dan gambar. Selain itu, keunggulan lain CMS video blog ini tersedia sourcenya dan free dengan lisensi GPL (General Public License). PHPMotion sendiri menggunakan PHP dan PERL sebagai scripting engine untuk fondasi sistemnya dan Backedn MySQL server untuk data storage (bisa juga dengan server database lainnya) serta menggunakan beberapa tool untuk video convert dan video capture seperti lame, ogg vorbis codec, mencoder, flvtool dan ffmpeg.

\section{LITERATURE REVIEW}

Dalam upaya mengoptimalkan penulisan jurnal, perlu dilakukan studi pustaka sebagai salah satu penerapan metode penelitian yang akan dilakukan. Manfaat dari Studi Pustaka (Literature Review) diantaranya untuk mengidentifikasikan kesenjangan (identify gaps), menghindari pembuatan ulang (reinventing the wheel), mengidentifikasikan metode yang pernah dilakukan, meneruskan penelitian sebelumnya, serta mengetahui orang lain yang spesialisasi dan area penelitiannya sama di bidang ini. Beberapa Literature Review tersebut adalah sebagai berikut :

1 Penelitian yang dilakukan oleh Barnard K. dan D.A. Forsyth dari Universitas California, Barkeley pada tahun 2001 yang berjudul "Learning The Semantics of Words And Pictures”. Penelitian ini membahas penyajian model statistik untuk mengatur koleksi gambar yang mengintegrasikan informasi semantik yang disediakan oleh teks asosiasi dan informasi visual yang disediakan oleh gambar. Model ini sangat menjanjikan untuk tugas-tugas pencarian informasi seperti database browsing dan mencari gambar berdasarkan teks dan gambar. 
Selanjutnya, model belajar hubungan antara teks dan gambar, dapat digunakan untuk aplikasi baru seperti mengasosiasikan kata dengan gambar tanpa pengawasan belajar bagi pengenalan objek.

2 Penelitian Jurnal Ilmiah yang dilakukan oleh Dewi Immaniar Desrianti, Untung Rahardja, dan Reni Mulyani dari Perguruan Tinggi Raharja pada tahun 2012 berjudul “Audio Visual One Of The Teaching Resources on iLearning” yang menjelaskan sebuah sistem pengajaran modern menggunakan iLearning yang memanfaatkan media audio visual sebagai konten pendukung. Serta ditunjang dengan fasilitas iPad yang di dalamnya terdapat aplikasi-aplikasi yang berhubungan dengan media audio visual seperti tutorial, gambar, animasi, musik, dan video. Media audio visual dalam iLearning ini membuat pembelajaran menjadi lebih menarik dan lebih terserap optimal oleh mahasiswa karena melibatkan dua sensor indra sekaligus yaitu audio visual dan visual.

3 Penelitian ini dilakukan oleh Untung Rahardja, Muhamad Yusup dan Eva Rosyifa dari Perguruan Tinggi Raharja tahun 2012 yang berjudul "Perancangan Aplikasi iLearning Majalah Online Dengan Menggunakan iOS Programming Pada Perguruan Tinggi”. Penelitian ini membahas sifat publikasi penyampaian informasi bersifat penting karena dapat membantu dan melakukan pencarian akan informasi yang sebelumnya tidak diketahui. Serta media publikasi masih berkaitan satu sama lain sehingga kebutuhan akan informasi sifatnya masih sangat tinggi dan dari sebagian tempat sifatnya masih sangat rendah dan proses pengupdatean akan informasi masih bersifat minim. Sehingga diharuskan melakukan perancangan aplikasi iLearningmajalahonlinedenganmenggunakan iOS Programming, yang diharapkan bisa diakses melalui iPhone dan iPad yang bisa di-download melalui iTunes demi meningkatkan peran media dalam perguruan tinggi supaya jauh lebih baik dan tentunya bermanfaat.

4 Penelitian yang dilakukan oleh Untung Rahardja, Sugeng Widada, dan Dewi Immaniar Desrianti dari Perguruan Tinggi Raharja pada tahun 2012 yang berjudul “KPM Sebagai Pedoman Produksi Multimedia Audio Visual Dan Broadcasting”. Penelitian ini menjelaskan memperkenalkan konsep yang disebut MAVIB konsep Produksi (KPM). Konsep Produksi MAVIB lebih diarahkan pada hal-hal yang kekhawatiran tentang tahapan yang harus dilakukan dalam proses desain, tahap ini mulai dari persiapan, produksi, hingga untuk pasca produksi. Melalui seluruh MAVIB Produksi Konsep, proses desain dapat diarahkan untuk berjalan secara teratur, sistematis dan menyederhanakan perjalanan setiap langkah dalam merancang sebuah media pasang iklan yang dibuat. Dalam artikel ini penulis menulis untuk memperkaya atau mengembangkan konsep desain kualitas yang baik dalam halpersiapan, sampai 
ke pos-produksi. Dalam artikel ini dijelaskan masalah yang dihadapi dalam konsep MAVIB produksi, baik dari segi desain, kekuatan dan kelemahan dari media dan kegunaan dari konsep produksi MAVIB media. Dalam implementasinya, dalam merancang media iklan, ditampilkan menggunakan CGI efek khusus dalam mendukung MAVIB Konsentrasi promosi, Departemen Informasi di Perguruan Tinggi Raharja. Disimpulkan bahwa, Kontribusi konsep produksi MAVIB.

5 Penelitian Jurnal Ilmiah yang dilakukan oleh Untung Rahardja, Muhamad Yusup, dan Fitriani dari Perguruan Tinggi Raharja pada tahun 2013 berjudul "Penerapan Proses Belajar Melalui Ilearning Video Tutorial (iVit) Pada Perguruan Tinggi” menjelaskan tentang cara yang efektif untuk belajar melalui video pada seluruh civitas akademika. iLearning Aplikasi Video Tutorial (iVit) yang digunakan di iPad adalah aplikasi yang efektif dan praktis untuk memaksimalkan proses belajar tanpa harus langsung bertatap muka, sehingga pengguna dapat mengulangi proses belajar dimana saja. Penerapan proses pembelajaran dengan aplikasi iVit, diharapkan dapat meningkatkan kulaitas pembelajaran di pendidikan tinggi.

Dari lima Literature Review yang ada, telah banyak penelitian mengenai multimedia serta pembahasannya perihal iLearning. Hasil literature review ini mendemonstrasikan landasan yang kokoh dan alasan yang kuat untuk mengembangkan sistem penyimpanan dokumentasi menjadi lebih baik lagi dalam memaksimalkan kegiatan belajar pada Perguruan Tinggi Raharja.

\section{IMPLEMENTASI}

Sebagai perwujudan rancangan sistem pada penelitian di atas, maka dibuatkanlah sebuah sistem informasi berbasis web yaitu media penyimpanan dokumentasi MAGICS. Dan berikut adalah tampilan dari sistem MAGICS.

\section{Tampilan logo MAGICS}

Gambar di bawah ini adalah tampilan logo MAGICS. Dalam logo MAGICS terdapat filosofi yang menggambarkan keterkaitan sistem MAGICS dengan Perguruan Tinggi Raharja. Setiap bentuk dan warna yang terkandung memiliki makna yang berbeda. 


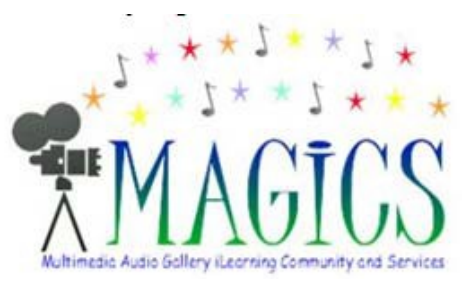

Gambar 8. Logo MAGICS

\section{Tampilan Home MAGICS}

Menu home merupakan tampilan yang pertama kali akan muncul saat member membuka website MAGICS. Di dalam menu home terdapat banyak navigasi yang akan memudahkan member dalam melakukan kegiatan di MAGICS. Salah satunya adalah form login. Pada menu home juga terdapat statistik MAGICS yang otomatis berubah seiring kegiatan penggunaan yang dilakukan member.

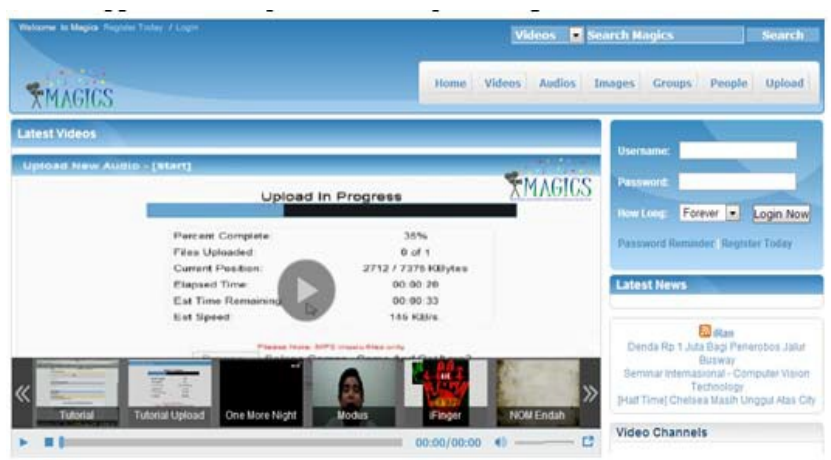

Gambar 9. Home MAGICS

Seluruh member dapat membuka website MAGICS melalui berbagai browser dengan URL www.magics.co.

\section{Tampilan Halaman Form Register MAGICS}

Form register berisi kolom pengisian data berupa nama, alamat email, username, password, dan security code. Data yang dimasukkan harus valid agar dapat diproses menjadi member. Hal ini bertujuan untuk menghindari adanya spammers yang mendaftar sebagai member MAGICS. Maka sistem pun sudah diatur untuk memiliki default email berdomain raharja.co dan raharja.info. 


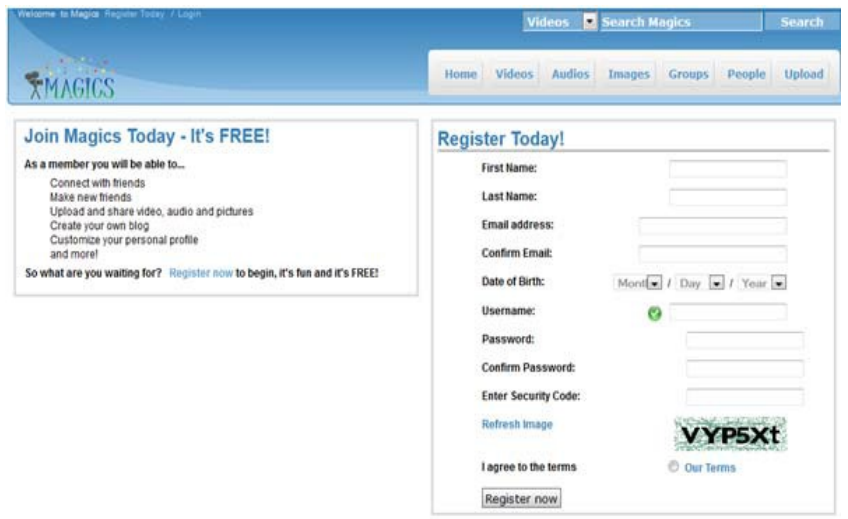

Gambar 10. Halaman Form Register MAGICS

\section{Tampilan Halaman Profile}

Pada halaman profile terdapat data pribadi beserta file yang sudah di-upload oleh member. Halaman ini memungkinkan member untuk memberikan postingan comment.

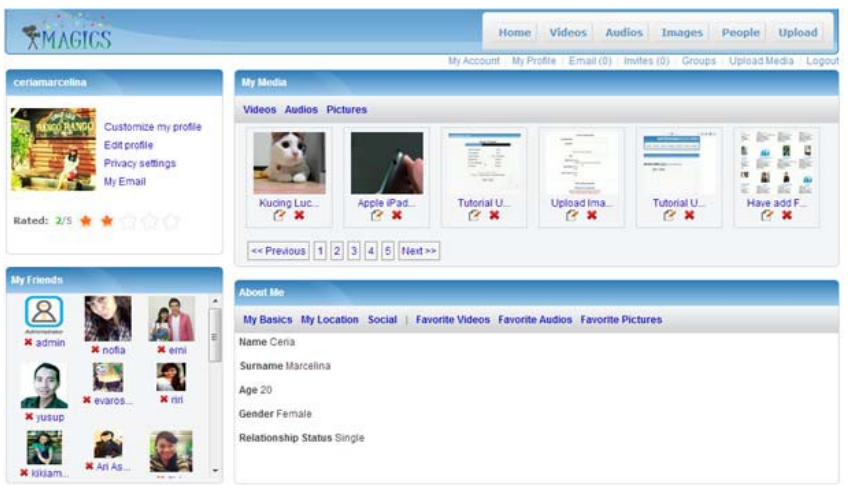

Gambar 11. Halaman Profile

5. Tampilan Halaman People

Halaman ini memperlihatkan data Pribadi Raharja yang telah terdaftar sebagai member MAGICS. Dalam halaman tersebut tertera keterangan dari masing-masing member mulai dari tanggal register, waktu keaktifan dalam pemakaian, jumlah video yang di-upload, dan jumlah teman. 


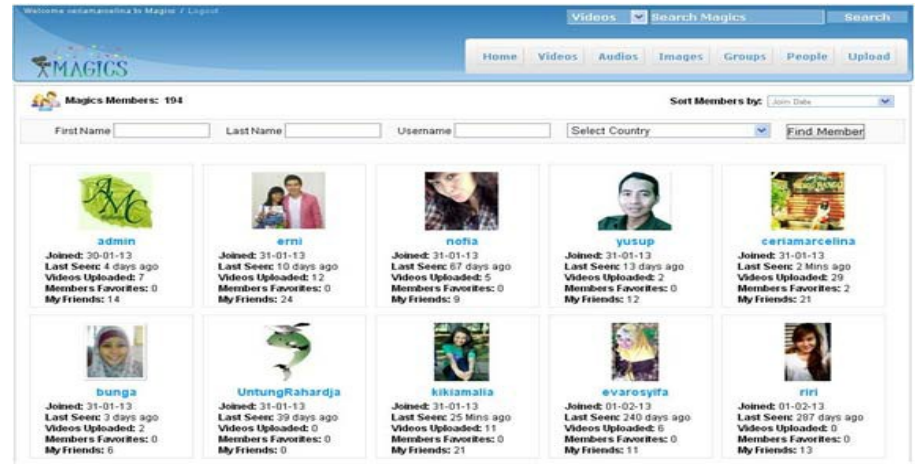

Gambar 12. Halaman People

6. Tampilan Halaman Upload

Halaman upload merupakan fasilitas yang disediakan MAGICS bagi member yang sudah login. Dalam halaman tersebut terdapat pilihan untuk upload file berupa video, audio, dan foto.

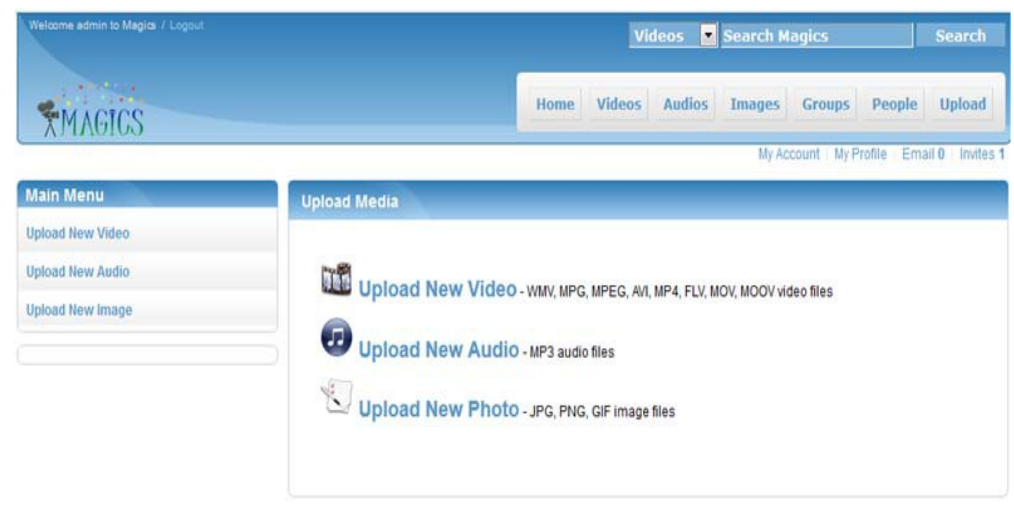

Gambar 13. Halaman Upload

\section{Tampilan Halaman Videos}

Halaman videos menampilkan file-file video yang telah di-upload member pada MAGICS. Dalam halaman tersebut juga terdapat keterangan dari masingmasing video seperti judul, deskripsi, rating, jumlah viewer, durasi video, tanggal upload, kata kunci, dan jumlah komentar. Member dapat melihatnya dengan mengklik video yang diinginkan. 

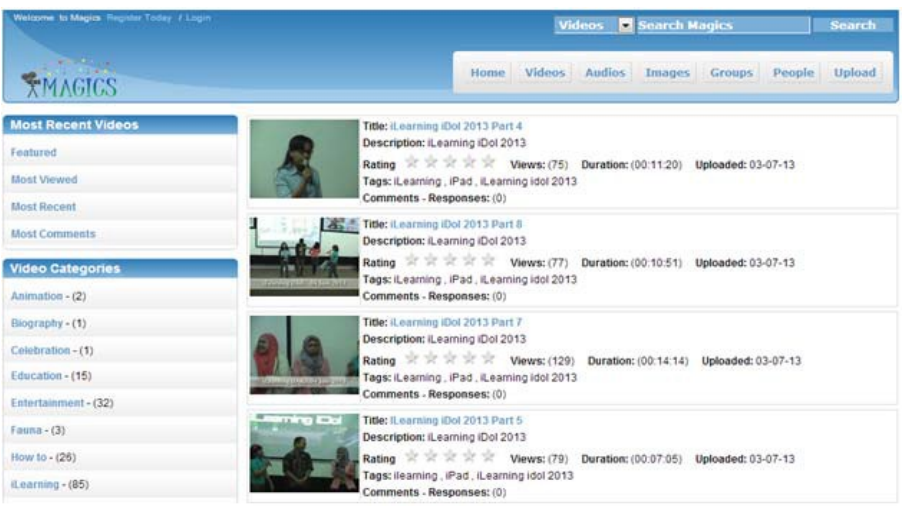

Gambar 14. Halaman Videos

8. Tampilan Halaman Audios

Dalam halaman audios terdapat file-file MP3 yang telah di-upload member pada MAGICS. Di halaman audio juga terdapat keterangan masing-masing audio yang sama seperti pada halaman video. Member dapat mendengarkannya dengan mengklikaudio yang diinginkan.

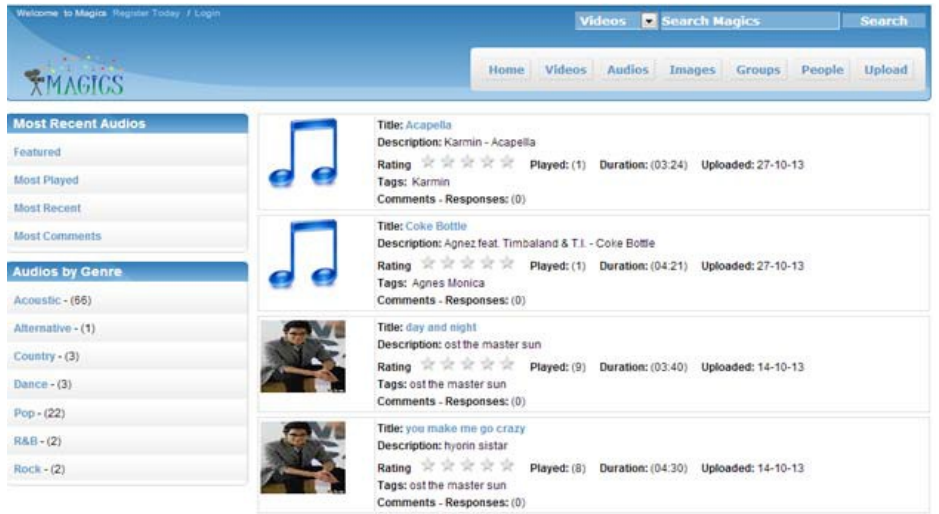

Gambar 15. Halaman Audios

9. Tampilan Halaman Images

Halaman images terdapat album yang terdiri dari gambar-gambar yang dimiliki para member MAGICS. Member dapat melihatnya dengan mengklik album yang ingin dilihat. 


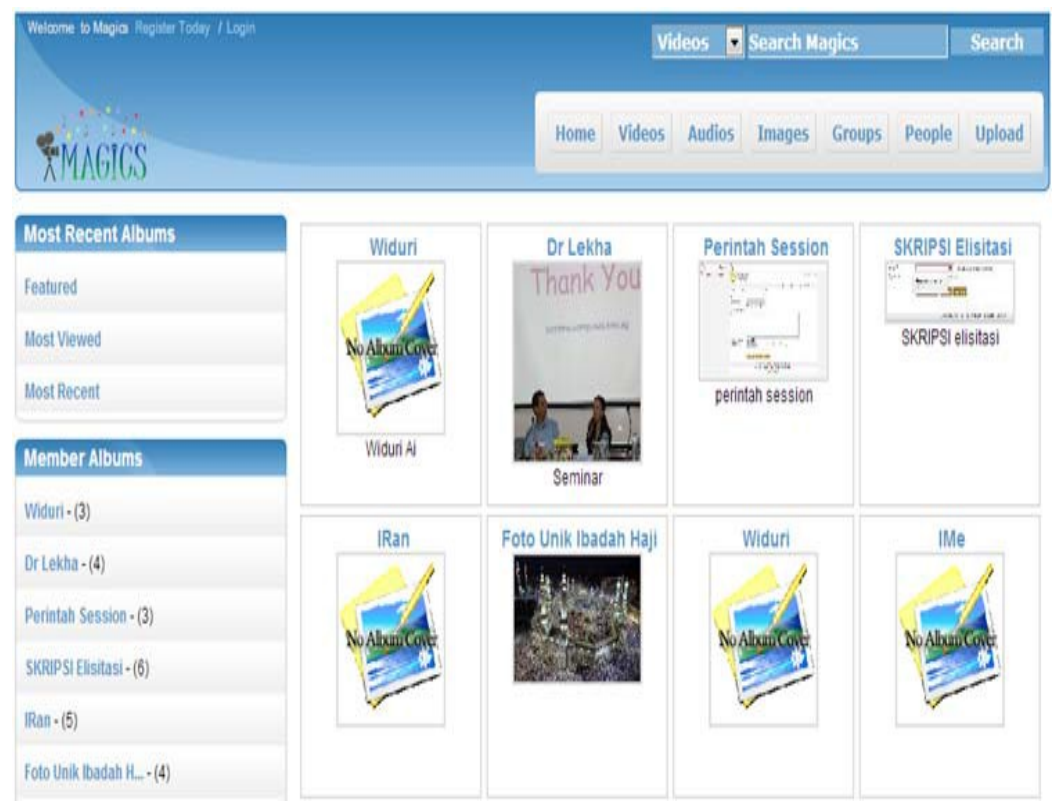

Gambar 16. Halaman Images

Pada halaman videos, audios dan images terdapat beberapa fiture pendukung, diantaranya social bookmarks, download, comment, rating, dan embed code.

\section{KESIMPULAN}

Multimedia memiliki peranan penting dalam terwujudnya konsep4B iLearning, untuk itu diperlukan sebuah media dalam menunjang penyimpanan dokumentasi. Green Documentation merupakan media penyimpanan yang saat ini berjalan di Perguruan Tinggi Raharja. Namun masih dikatakan bahwa sistem tersebut belum optimal dikarenakan belum terpenuhinya seluruh kebutuhan akses dan penyimpanan file.

MAGICS (Multimedia Audio Gallery iLearning Community and Services) merupakan satu solusi sebagai wadah dokumentasi dan file sharing. Dengan menerapkan MAGICS, terdapat beberapa keunggulan yaitu sistem bersifat online dan terpusat, proses pencarian lebih efektif dengan tersedianya berbagai fitur, diberikannya akses kepada Pribadi Raharja sebagai memberuntuk dapat melakukan 
upload file secara terstruktur. Selain itu memudahkan mahasiswa untuk berbagi file (file sharing) berupa foto, audio maupun video tentang informasi kegiatan kampus.

\section{DAFTAR PUSTAKA}

[1] Rahardja, Untung. 2011. “iLearning an Effective Learning Method for Higher Education”.

[2] Community, eWolf. 2012. "Panduan Internet Paling Gampang”. Yogyakarta: Cakrawala.

[3] Bukhori, Akhmad. 2013. "Definisi Multimedia Menurut Beberapa Ahli”. Diakses pada tanggal 28 Oktober 2013 dari http:// akhmadbukhori31.blogspot.com/2013/03/definisi-multimedia-menurutbeberapa.html.

[4] H. Wijoyo, Widodo. 2010. “Konsep dan Definisi Dokumentasi”. Diakses pada tanggal 28 Oktober 2013 dari http://widodo.staff.uns.ac.id/2010/03/ 08/ringkasan-modul-1-konsep-dan-definisi-dokumentasi/.

[5] Rumani, Sri. 2009. “Dokumentasi, Kearsipan, Informasi dan Perpustakaan”. Diakses pada tanggal 28 Oktober 2013 dari http://srirumani.wordpress.com/ 2009/06/13/21/.

[6] Sihotang, Rika Monika. 2012. “Pengertian dan Sejarah Open Source”. Diakses pada tanggal 28 Oktober 2013 dari http://rikamonika.blogspot.com/2012/ 04/pengertian-dan-sejarah-open-source.html.

[7] Ferianto, Imam. 2008. “Membuat Situs Youtube Clone”. Diakses pada tanggal 28 Oktober 2013 dari http://www.theferianto.com/2008/09/07/membuatsitus-youtube-clone/.

[8] K. Barnard, dan D. A. Forsyth. 2001. "Learning the Semantics of Words and Pictures”. In International Conference on Computer Vision, pages II:408415.

[9] Imaniar, Dewi, Untung Rahardja, dan Reni Mulyani. 2012. “Audio Visual One of The Teaching Resources on iLearning”. CCIT Journal ISSN : 1978-8282. Vol. 5 No. 2. Tangerang : Perguruan Tinggi Raharja.

[10] Rahardja, Untung, Muhamad Yusup, Eva Rosyifa . 2012. "Perancangan Aplikasi iLearning Majalah Online Dengan Menggunakan iOS Programming Pada Perguruan Tinggi”. CCIT Journal ISSN : 1978-8282. Tangerang : Perguruan Tinggi Raharja.

[11] Rahardja, Untung, Sugeng Widada, dan Dewi Immaniar Desrianti. 2012. "KPM Sebagai Pedoman Produksi Multimedia Audio Visual Dan 
Broadcasting”. CCIT Journal ISSN : 1978-8282. Tangerang : Perguruan TinggiRaharja.

[12] Rahardja, Untung, Muhamad Yusup, dan Fitriani. 2013. "Penerapan Proses Belajar Melalui iLearning Video Tutorial (iVit) Pada Perguruan Tinggi”. CCIT Journal ISSN : 1978-8282 Vol. 6 No. 2. Tangerang : Perguruan Tinggi Raharja. 